\title{
Comparison of the two point bending and four point bending test methods for aged asphalt concrete field samples
}

\author{
Lily D. Poulikakos • Michel Pittet • \\ Andre-Gilles Dumont • Manfred N. Partl
}

Received: 6 March 2014/ Accepted: 13 June 2014/Published online: 22 June 2014

(C) RILEM 2014

\begin{abstract}
Complex modulus and fatigue behavior are important characteristics for all materials. Some European countries have developed performance oriented requirements for bituminous mixtures. Using such requirements it is expected that the life of pavements can be improved. According to the European standards, these properties are characterized by various methods including two point bending (2PB) on trapezoidal specimen and four point bending (4PB) on prismatic specimen. It is known that the fatigue results obtained are highly dependent, in addition to the mixture variables and environmental variables, on specimen fabrication procedure and test equipment and procedure. Therefore the question remains how comparable are the results obtained from these tests? Up to date, a significant amount of data on comparison of the results of such tests is absent. This paper
\end{abstract}

L. D. Poulikakos $(\varangle) \cdot$ M. N. Partl

Empa, Swiss Federal Laboratories for Material Science and Technology, Überlandstrasse 129, 8600 Dübendorf, Switzerland

e-mail: lily.poulikakos@empa.ch

M. N. Partl

e-mail: manfred.partl@empa.ch

M. Pittet · A.-G. Dumont

Laboratoire des voies de circulation, Ecole polytechnique fédérale de Lausanne, Lausanne, Switzerland e-mail: michel.pittet@epfl.ch

A.-G. Dumont

e-mail: andre-gilles.dumont@epfl.ch presents results of a Swiss inter-laboratory study on $2 \mathrm{~PB}$ and $4 \mathrm{~PB}$ tests for complex modulus and fatigue conducted on a wide pallet of specimen produced from aged field sections. The results show that a good linear regression for complex modulus values were obtained, however, the fatigue performance ranking obtained from the two tests were dissimilar.

Keywords Two point bending - Four point bending . Complex modulus · Fatigue $\cdot$ Asphalt concrete .

Performance requirements

\section{Introduction}

Complex modulus and fatigue behavior are important characteristics for all engineering materials. A recent state of the art report by Rilem has made the link between repeated loading as a significant contributor to rutting and fatigue in bituminous materials [1]. According to the European standards for bituminous materials these properties can be characterized using five methods $[2,3]$. Those are two-point bending on trapezoidal specimens, two point bending on prismatic shaped specimen, three point bending test on prismatic shaped specimens, four point bending test on prismatic specimens and indirect tensile test on cylindrically shaped specimens. Fatigue cracking is considered to be one of the primary failure modes in asphalt concrete and methods to ascertain fatigue behavior are an 
important aspect of performance based requirements. Therefore, aside from the standard tests listed above there are many other characterization methods that are not as yet standardized [4]; however the focus of this paper is on the standardized methods. Fatigue failure can manifest itself in the form of reflective cracking as a result of repeated traffic loading [5].This paper reports on results of methods currently in use in Switzerland i.e. two point bending on trapezoidal specimens (2PB-TR, here referred to as 2PB) and four point bending on prismatic specimens (4PB-PR, here referred to as $4 \mathrm{~PB}$ ). The tests are performed on field compacted bituminous materials under sinusoidal loading, using different types of specimens and supports. The procedure is used to rank bituminous mixtures on the basis of complex modulus, as indication of relative performance in the pavement, to obtain data for estimating the structural behavior in the road and to judge test data according to specifications for bituminous mixtures. The fatigue behavior of the material is used to gain insight into the pavement's resistance to repeated loads affecting the pavements serviceability and life.

Some European countries have developed performance based requirements for complex modulus and fatigue resistance. Using such requirements it is expected that the life of pavements can be improved as indicated by some evidence in the literature [6-9]. It has been shown that the fatigue results obtained are highly dependent, in addition to the mixture variables and environmental variables, on specimen fabrication procedure, test equipment and testing procedure [10]. Specifically a coefficient of variation of $41 \%$ in fatigue life based on test equipment and $33 \%$ based on the method of specimen preparation comparing rolling wheel compactor and the kneading compactor was measured. This data has led to the development of different specifications for the different types of tests. For example, In Hungary requirements for stiffness and fatigue are specified based on test method used, with different temperature and frequencies defined for the different test methods [11]. Currently in Switzerland, performance oriented requirements exist for a special type of pavement (AC-EME) only [12]. Where, EME is the French abbreviation of enrobé module élevé which stands for high modulus asphalt concrete. The requirements specified are for complex modulus and for fatigue behavior obtained according to the European standards mentioned above. The minimum required complex modulus $S_{\min }$ is defined at $15{ }^{\circ} \mathrm{C}, 10 \mathrm{~Hz}$ to be $11,000 \mathrm{MPa}$. Furthermore, the fatigue resistance is to be determined only using the two point bending test on trapezoidal specimen and requiring the minimum strain $\varepsilon_{6}$, which is defined where $10^{6}$ cycles are reached (at $10^{\circ} \mathrm{C}, 25 \mathrm{~Hz}$ ) to be $100 \mu \varepsilon(\mu \mathrm{m} / \mathrm{m})$.

Although the 4PB test is considered not trivial to perform, it has become a standard test method worldwide, as it allows a significant section of the specimen to undergo fatigue loading. For example, in the US the 4PB is used as basis for the mechanistic empirical design guide (MEPDG) as one result of the SHRP program [10]. It is still the topic of different international conferences on $4 \mathrm{~PB}$ fatigue testing, such as [13] and intensive inter-laboratory activities, e.g. by RILEM [5]. Matthews et al. [14] give an overview from the US, where they investigated laboratory fatigue testing procedures for asphalt concrete mixtures. They summarized the steps necessary to measure the fatigue life in the laboratory and identified advantages and disadvantages of different methods. The three most promising methods were considered to be simple flexure, diametral fatigue, and tests based on fracture mechanics principles. The use of the $2 \mathrm{~PB}$ test is more common in many European countries. The results of a Rilem inter-laboratory study on various fatigue tests were presented by Di Benedetto et al. [5] which shows that the classical fatigue approach is considerably influenced by test type and mode of loading (controlled stress or strain). They showed that damage theory models may serve towards a rational mechanistic fatigue characterization model. The experience with 4PB tests in Portugal indicated that using laboratory produced samples at $20^{\circ} \mathrm{C}$ test temperature using any type of test set up can lead to variability in complex modulus results of $\pm 15-20 \%$. The results for fatigue tests were reported as being similar [15]. A Rilem inter-Laboratory study [16] has summarized the results of complex modulus measurements and fatigue behavior from fifteen laboratories. Various test set-ups were used including two 2PB and three 4PB setups from Europe. They presented results for complex modulus with measurements using small strains, and therefore in the linear elastic range of the material from the laboratories that used $4 \mathrm{~PB}$ and $2 \mathrm{~PB}$. These tests were carried out on laboratory produced specimen and were conducted at a temperature of 0 and $20^{\circ} \mathrm{C}$ and at frequency of 1 and $10 \mathrm{~Hz}$ each. 
Results indicate that there is wider scatter in complex modulus at higher temperature and lower scatter in phase angle. Comparing only $2 \mathrm{~PB}$ and $4 \mathrm{~PB}$, a maximum difference of $17 \%$ in complex modulus at $20{ }^{\circ} \mathrm{C}$ and $1 \mathrm{~Hz}$ and $24 \%$ in phase angle at $0{ }^{\circ} \mathrm{C}$ and $10 \mathrm{~Hz}$ was measured. The general conclusion was that the bending tests were in close agreement compared to other type of tests performed in the study.

Theoretically the modulus obtained in the linear visco-elastic region is a temperature dependent material property that should not vary significantly when using different test methods. However, as discussed above, depending on the test procedure used, a considerable variation in the results can be expected, thereby bringing up the question of performance oriented requirements and their validity for various test conditions.

As indicated above the information available in the literature is overwhelmingly on laboratory prepared specimen. Performance of field compacted specimen is missing for the most part.

The goal of this paper is to present results of a Swiss inter-laboratory study implementing $2 \mathrm{~PB}$ and $4 \mathrm{~PB}$ tests for determination of complex modulus and fatigue behavior conducted on a wide pallet of specimen produced from pavement slabs cut from aged field sections. These tests on slabs where performance was known allowed to link lab fatigue behavior with real in situ behavior. On the basis of the obtained results the validity of performance based standards using one test method is discussed and recommendations are made. Furthermore, the requirements pertaining to sample size, NMAS (nominal maximum aggregate size) and cutting all surfaces of specimens are not always practically applicable when field slabs are considered and this point is further discussed in the following sections.

\section{Materials and sample preparation}

In this study, two wearing courses, three binder courses and three base courses were selected from high performance Swiss motorways as shown in Tables 1 and 2. These sections were chosen in order to allow a wide palette of slabs to be tested. The choice of field slabs allows evaluating sections that were exposed to traffic inducing structural defects, climate and aging. This allowed more realistic specimen leading to more realistic comparisons in terms of performance. Although the pavements were aged in situ, its conditions were not recorded and visual inspection did not show any gross defects. A total of 252 experiments were performed on these eight types of mixes. The choice of using specimen cut from pavement slabs as opposed to laboratory prepared samples was made in order to eliminate the effect of various compaction methods that as discussed earlier can have a significant effect on the results [10]. However, it should be noted that this selection meant that the samples were at various stages of aging and mechanical deterioration which in turn have a direct effect on the obtained results.

The material specifications are shown in Table 2 with the mixture gradation in Fig. 1. The nominal maximum aggregate size (NMAS) of the mixtures was from 22.4 to $8 \mathrm{~mm}$. As these were field slabs at different stages of aging ( 1 year up to 14 years) not all data was available. However, all layers and mixtures were within the Swiss standards at the time of construction. The known binder types were straight run and SBS polymer modified. The binder contents by mass of total mix are listed in Table 2; they vary from 4.26 to $6.88 \%$. The mixture designations are standard Swiss designations: asphalt concrete (AC), stone mastics (SMA), rough asphalt (AC MR) and high modulus (EME). The mix classification based on traffic volume is: High $(\mathrm{H})$ and standard $(\mathrm{S})$. The paving location is as follows: no designation means wearing course with binder course (B) and base course (T). The air void content of the cores from the slabs varied from 1.5 to $9.2 \%$.

Table 1 lists the specimen dimensions for modulus and fatigue tests. It is clear from the prismatic and trapezoidal specimen sizes that the $2 \mathrm{~PB}$ and $4 \mathrm{~PB}$ specimen have different thicknesses. This thickness has a direct effect on the stiffness of the specimen and the resulting values for modulus and fatigue. According to the standards [2,3], all surfaces should be cut and the specimen should be sawed from the center of the slab allowing a $20 \mathrm{~mm}$ border however, practically this condition could not be fulfilled in all cases. For example, in the case of the two wearing courses ( $\mathrm{C} 1$ and D1) this condition was not met due to the limited layer thickness. Furthermore, the standard limits the tests for specimen with maximum aggregate size of up to $20 \mathrm{~mm}$. This needs to be corrected as some European countries such as Switzerland have different 
Table 1 Specimen dimensions, mixtures and layer type

\begin{tabular}{|c|c|c|c|c|c|c|}
\hline \multirow[t]{2}{*}{ Type pavement } & \multirow[t]{2}{*}{ Layer } & \multirow{2}{*}{$\begin{array}{l}\text { Mix } \\
\text { Nr. }\end{array}$} & \multirow{2}{*}{$\begin{array}{l}\text { Depth } \\
(\mathrm{mm})\end{array}$} & \multirow{2}{*}{$\begin{array}{l}\text { NMAS } \\
(\mathrm{mm})\end{array}$} & \multicolumn{2}{|c|}{ Specimen dimensions $(\mathrm{mm})$} \\
\hline & & & & & $2 \mathrm{~PB}$ & $4 \mathrm{~PB}$ \\
\hline \multirow[t]{2}{*}{ Wearing course } & SMA11 & $\mathrm{C} 1$ & 40 & 11 & $56 \times 25 \times 25 \times 250$ & $40 \times 40 \times 450$ \\
\hline & AC MR 8 & D1 & 30 & 8 & $56 \times 25 \times 25 \times 250$ & $30 \times 30 \times 450$ \\
\hline \multirow[t]{3}{*}{ Binder course } & AC B $22 \mathrm{H}$ & B2 & 90 & 22 & $70 \times 25 \times 25 \times 250$ & $50 \times 50 \times 450$ \\
\hline & AC B 22 S (HMT $22 \mathrm{~S}$ ) & $\mathrm{C} 2$ & 90 & 22 & $70 \times 25 \times 25 \times 250$ & $50 \times 50 \times 450$ \\
\hline & AC B $22 S$ & D2 & 70 & 22 & $70 \times 25 \times 25 \times 250$ & N/A \\
\hline \multirow[t]{3}{*}{ Base course } & AC T $22 \mathrm{H}$ & B3 & 70 & 22 & $70 \times 25 \times 25 \times 250$ & $50 \times 50 \times 450$ \\
\hline & AC EME 22 (BBHM 22) & $\mathrm{F} 3$ & 80 & 22 & $70 \times 25 \times 25 \times 250$ & $50 \times 50 \times 440$ \\
\hline & AC T 22 S (HMT 22 S) & G3 & 80 & 22 & $70 \times 25 \times 25 \times 250$ & N/A \\
\hline
\end{tabular}

Designation in parenthesis is according to the standards when the layer was placed. Dimensions are as follows: $2 \mathrm{~PB}$ : wider base $\times$ height $\times$ short base $\times$ length; 4 PB: base $\times$ height $\times$ length

sieve sizes that allow $22 \mathrm{~mm}$ aggregates. The tests performed in this project included samples with maximum aggregate size, $D$ of $22 \mathrm{~mm}$.

\section{Test methods and experimental program}

The $2 \mathrm{~PB}$ and $4 \mathrm{~PB}$ tests are similar in many senses and dissimilar in other. For example they are similar in the sense that they produce a flexural stress state that incorporates tension-compression in the specimen [17]. The difference in the two tests is firstly regarding specimen size shown in Table 1, the direction of cutting and testing and the experimental setup. Figure 2 illustrates how the specimens are cut from the slabs. The different setups shown in Fig. 3 result in the load application direction with respect to the specimen that is different. Dondi et al. [17] have presented a novel loading set up applying the 2PB load vertically and installing the specimen horizontally as they believe this loading direction affects the results. The 4PB set up creates the highest flexural stress state between the supports; failure usually occurs close to the center of the specimen. The 2PB test set up creates a state of stress with the highest stress state being about $1 / 3$ from the glued bottom of the sample and this is where the sample usually fails.

Two laboratories were involved in performing the experiments reported here using the European standards for measurement of complex modulus and fatigue resistance employing sinusoidal waveforms. 18 specimens were tested for each material type. Complex modulus tests were performed at temperatures of 10,15 and $20{ }^{\circ} \mathrm{C}$ each at 3,10 and $25 \mathrm{~Hz}$ loading frequencies. Fatigue tests were performed at $20^{\circ} \mathrm{C}$ and $25 \mathrm{~Hz}$ for $4 \mathrm{~PB}$ (with one exception) and $10{ }^{\circ} \mathrm{C}$ and $25 \mathrm{~Hz}$ for $2 \mathrm{~PB}$. These different testing conditions are what is used typically by the two labs.

During a fatigue test three distinct regions can be identified. In region one, the reduction in stiffness decelerates, in region II the reduction is almost linear and in region III the reduction accelerates as shown in Fig. 4 . The number of cycles $N_{\mathrm{f} / 50}$ where the initial $E^{*}$ modulus has been reduced by $50 \%$ can be taken as fatigue failure criterion. Also schematically shown in Fig. 4 is the strain controlled fatigue failure curve. This Wöhler type of curve shows that continuously applying high strain amplitudes creates failure after fewer numbers of cycles than when applying low strain amplitudes. This allows defining another classical failure criterion $\varepsilon_{6}$ which denotes the applied strain (i.e. strain amplitude) where fatigue failure occurs just after 1 million cycles.

The 4PB setup used here includes a novel clamping system that was designed to account for relaxation in the beam and allow the required degrees of freedom at the clamping locations. The complex modulus is calculated from the measured force and relative deflection between the inductive deformation sensor (LVDT) placed in the center and a second one under one support. Sampling takes place after the first 100 cycles until 200. For every cycle 50 values are recorded. Here the complex modulus refers to the absolute value of the complex number.

In the 2PB test, the modulus calculation is achieved through the following steps: force and displacement 
Table 2 Type of mixture, binder type, air void content, binder content of cores, richness modulus, characteristics of the recovered binder

\begin{tabular}{|c|c|c|c|c|c|c|c|c|c|c|}
\hline Designation & $\mathrm{C} 1$ & D1 & B2 & $\mathrm{C} 2$ & \multicolumn{2}{|l|}{ B3 } & \multicolumn{2}{|l|}{$\mathrm{F} 3$} & $\mathrm{D} 2^{\mathrm{a}}$ & $\mathrm{G}^{\mathrm{a}}$ \\
\hline Section & A3 Aargau & Bern & $\begin{array}{l}\text { A2 Bellinzona sud- } \\
\text { Bellinzona nord }\end{array}$ & A3 Aargau & \multicolumn{2}{|c|}{$\begin{array}{l}\text { A2 Bellinzona sud- } \\
\text { Bellinzona nord }\end{array}$} & \multicolumn{2}{|c|}{$\begin{array}{l}\text { A1 Yverdon-Bern- } \\
\text { Tronçon Arrissoules }\end{array}$} & N1 05 Aargau & $\begin{array}{l}\text { A1 Payerne- } \\
\text { Avenches }\end{array}$ \\
\hline Type (new des.) & SMA 11 & AC MR 8 & AC B $22 \mathrm{H}$ & AC B $22 \mathrm{~S}$ & \multicolumn{2}{|l|}{ AC T $22 \mathrm{H}$} & \multicolumn{2}{|c|}{ AC EME 22} & AC B $22 \mathrm{~S}$ & AC T $22 \mathrm{~S}$ \\
\hline Type (old des.) & SMA 11 & NA & NA & HMT $22 \mathrm{~S}$ & \multicolumn{2}{|l|}{ NA } & \multicolumn{2}{|c|}{ BBHM 22} & NA & HMT $22 \mathrm{~S}$ \\
\hline Binder type & NN & NN & PmB C 30/50-58 & NN & \multicolumn{2}{|l|}{$\mathrm{NN}$} & \multicolumn{2}{|c|}{ B $10 / 20$} & NN & B $55 / 70$ \\
\hline Layer & Wearing 1 & Wearing 2 & Binder 1 & Binder 2 & \multicolumn{2}{|l|}{ Base 1} & \multicolumn{2}{|c|}{ Base 2} & Binder 3 & Base 3 \\
\hline Laying year & 1998 & 2008 & 2007 & 1998 & \multicolumn{2}{|l|}{2007} & \multicolumn{2}{|l|}{1999} & 2008 & 1995 \\
\hline Sampling year & 2009 & 2009 & 2009 & 2009 & \multicolumn{2}{|l|}{2009} & \multicolumn{2}{|l|}{2009} & 2009 & 2009 \\
\hline Years in service & 11 & 1 & 2 & 11 & \multicolumn{2}{|l|}{2} & \multicolumn{2}{|l|}{10} & 1 & 14 \\
\hline \multicolumn{2}{|l|}{ Sieve size $(\mathrm{mm})$} & \multicolumn{9}{|c|}{$\%$ Passing (by mass) } \\
\hline \multicolumn{2}{|l|}{31.5} & - & - & 100.0 & 100.0 & - & & 100.0 & 100.0 & - \\
\hline \multicolumn{2}{|l|}{22.4} & - & - & 96.5 & 97.0 & 100.0 & & 98.9 & 98.8 & 100.0 \\
\hline \multicolumn{2}{|l|}{16} & 100.0 & 100.0 & 84.9 & 90.5 & 91.7 & & 83.1 & 86.6 & 91.2 \\
\hline \multicolumn{2}{|l|}{11.2} & 95.6 & 99.3 & 70.3 & 76.8 & 77.6 & & 71.2 & 72.9 & 73.9 \\
\hline \multicolumn{2}{|l|}{8} & 65.0 & 94.5 & 60.0 & 66.1 & 66.4 & & 58.9 & 61.6 & 60.6 \\
\hline \multicolumn{2}{|l|}{5.6} & 37.9 & 64.6 & 50.2 & 53.3 & 56.2 & & 48.1 & 51.6 & 49.5 \\
\hline \multicolumn{2}{|l|}{4} & 32.1 & 37.1 & 42.5 & 43.5 & 48.4 & & 40.2 & 43.5 & 44.3 \\
\hline \multicolumn{2}{|l|}{2} & 25.7 & 24.3 & 31.5 & 30.9 & 34.9 & & 28.9 & 29.6 & 29.4 \\
\hline \multicolumn{2}{|l|}{1} & 20.6 & 18.8 & 26.0 & 22.1 & 29.7 & & 23.5 & 21.1 & 20.6 \\
\hline 0.5 & & 17.5 & 15.5 & 16.7 & 16.5 & 17.6 & & 15.0 & 16.0 & 15.4 \\
\hline 0.25 & & 15.1 & 12.6 & 13.1 & 12.8 & 11.8 & & 11.6 & 12.2 & 12.0 \\
\hline 0.125 & & 12.8 & 10.3 & 10.2 & 10.2 & 7.8 & & 9.0 & 9.3 & 9.4 \\
\hline 0.063 & & 10.5 & 7.9 & 7.8 & 7.8 & 5.3 & & 6.8 & 7.1 & 7.3 \\
\hline Binder ( $\%$ by wg & of total mix) & 6.88 & 5.69 & 4.65 & 4.58 & 4.53 & & 5.17 & 4.34 & 4.26 \\
\hline Richness modulu & $\mathrm{R}(-)^{\mathrm{b}}$ & 4.24 & 3.62 & 2.94 & 2.90 & 3.06 & & 3.40 & 2.78 & 2.71 \\
\hline Voids cores $(\% \mathrm{~b}$ & ol. $)^{\mathrm{c}}$ & $4.1(\mathrm{sd} 0.81)$ & $8.5($ sd 0.73$)$ & $3.5(\mathrm{sd} 0.92)$ & $3.2(\mathrm{sd} 0.76)$ & $9.2(\mathrm{sd}$ & 1.55) & $8.9(\mathrm{sd} 2.50)$ & $1.5(\mathrm{sd} 0.66)$ & 4.5 (sd 0.73) \\
\hline Bitumen recovery & sample & & & & & & & & & \\
\hline Penetration 25 & $0.1 \mathrm{~mm})$ & 43 & 40 & 30 & 45 & 7 & & 9 & 34 & 31 \\
\hline $\mathrm{R} \& \mathrm{~B}\left({ }^{\circ} \mathrm{C}\right)$ & & 54.5 & 70.0 & 68.8 & 57.9 & 81.6 & & 81.7 & 67.7 & 64.8 \\
\hline IP $(-)$ & & -0.5 & 2.3 & 1.4 & 0.3 & 0.6 & & 1.0 & 1.5 & 0.8 \\
\hline
\end{tabular}

$N N$ not known, $s d$ standard deviation, $N A$ not applicable

a Tested by one lab

${ }^{b}$ Calculated based on SN EN 640 431-1b-NA

c Standard deviation based on 26 or 32 samples 
Fig. 1 Mixture gradation chart

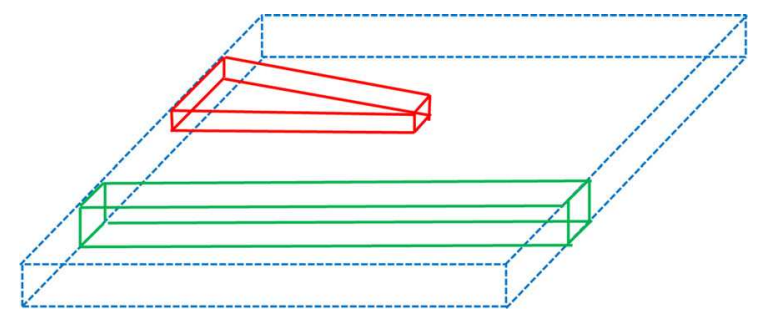

Fig. 2 Illustration depicting the 2PB-TR (red) and 4PB-PR (green) specimens shown within the pavement (blue), (not to scale). (Color figure online)

signals are recorded in $1 \mathrm{~s}$ intervals. Sampling rate is adapted to measurement frequency. Both signals are analyzed with an algorithm to extract their amplitudes and their phase difference (Labview's software signal processing algorithm). The values of amplitudes (force and displacement) as well as the phase angle

Fig. 3 Loading configuration of $2 \mathrm{~PB}$ test left and $4 \mathrm{~PB}$ right, dimensions in $\mathrm{mm}$

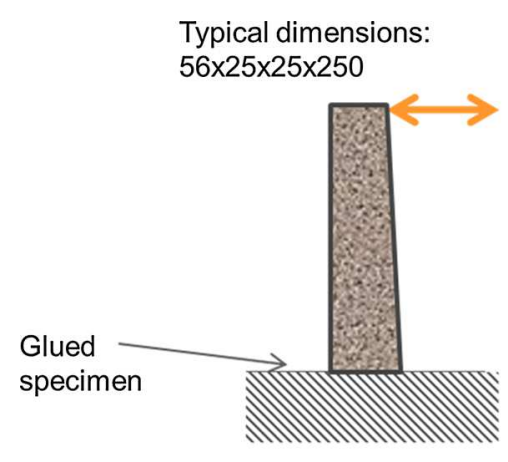

2PB are filtered with the calculation of a moving average of n previous values. The $n$ value is determined by the operator (usually $n=20$ ). The final measurement values are noted generally $45 \mathrm{~s}$ to $1 \mathrm{~min}$ after setting the test conditions. This delay meets the stabilization time recommended by the EN 12697-26:2004 standard (30 s to $2 \mathrm{~min}$ ) and is sufficient to fill entirely the moving average buffer with values corresponding to the measurement steady state.

\section{Results and discussion}

\subsection{Complex modulus}

The characterization of the material in the linear viscoelastic region was done using both tests.

\section{Typical dimensions: $50 \times 50 \times 450$}

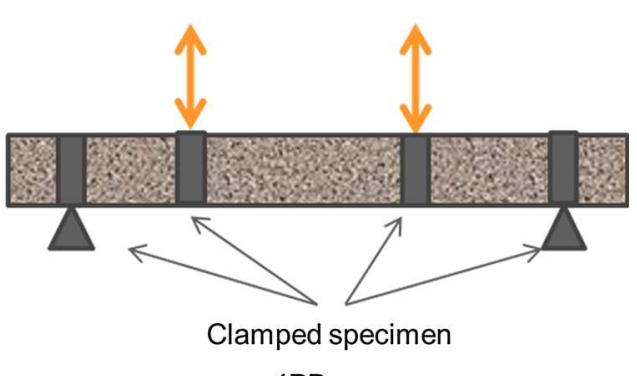

4PB 


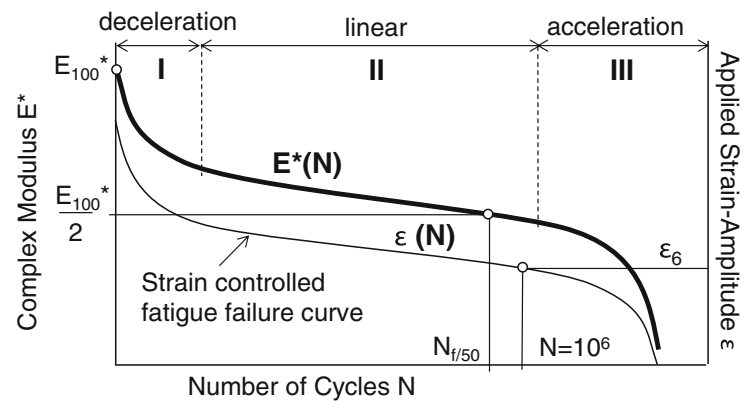

Fig. 4 Fatigue curves (complex modulus $E^{*}(N)$ and strain controlled failure curve $\varepsilon(N)$ ) showing three distinct regions and different definitions for fatigue failure criteria

Complex modulus and phase angle were determined at the 100th cycle as prescribed by the standard with the values presented being average values for four specimens in Figs. 5 and 6.

Figure 5 indicates that the complex modulus values of the wearing courses at $15{ }^{\circ} \mathrm{C}$ and $10 \mathrm{~Hz}$ frequency are slightly lower than that of the binder and base courses. This could be a result of the type of binder and binder content and void content as the wearing courses have higher binder contents (Table 2) with smaller NMAS. The phase angles of the wearing courses were higher than the binder and base courses (Fig. 6). The higher phase angle is indicative of more viscous property of the wearing courses. The higher binder content and type of binder of the wearing courses is a cause of these being more viscous. As mentioned earlier and shown in Table 2, all samples were field aged. However, the effect of age on these properties is difficult to pinpoint and no trend could be identified.

Comparison of the two test methods indicates that the complex modulus values of $4 \mathrm{~PB}$ are consistently higher than for $2 \mathrm{~PB}$ tests, in particular for wearing courses. This is in line with international studies as discussed in Sect. 1. The Rilem study [5] indicated a maximum difference of $17 \%$ in complex modulus and $-24 \%$ in phase angle between the $2 \mathrm{~PB}$ and $4 \mathrm{~PB}$ tests. Furthermore, the Rilem study was carried out on laboratory compacted specimens, resulting in more homogeneous samples in terms of aging, climatic exposure and compaction method than the field samples used in the current study. The difference in the results presented here is partly due to the fact that as discussed earlier, the 4PB and 2PB tests result in different stress states in the material. Therefore it is not expected to achieve the same results from the two tests. Furthermore, the 4PB test exposes a larger area of the material i.e. between the supports to fatigue loading, and can therefore identify weak positions better than the 2PB test where a smaller area is loaded. An additional effect is the mass affecting inertia in dynamic measurements as the two tests use different specimen sizes with different masses. The different
Fig. 5 Initial complex modulus values, $E_{100}^{*}$, of all the materials tested at $15{ }^{\circ} \mathrm{C}$ and $10 \mathrm{~Hz}$ as required by the Swiss annex to the standard

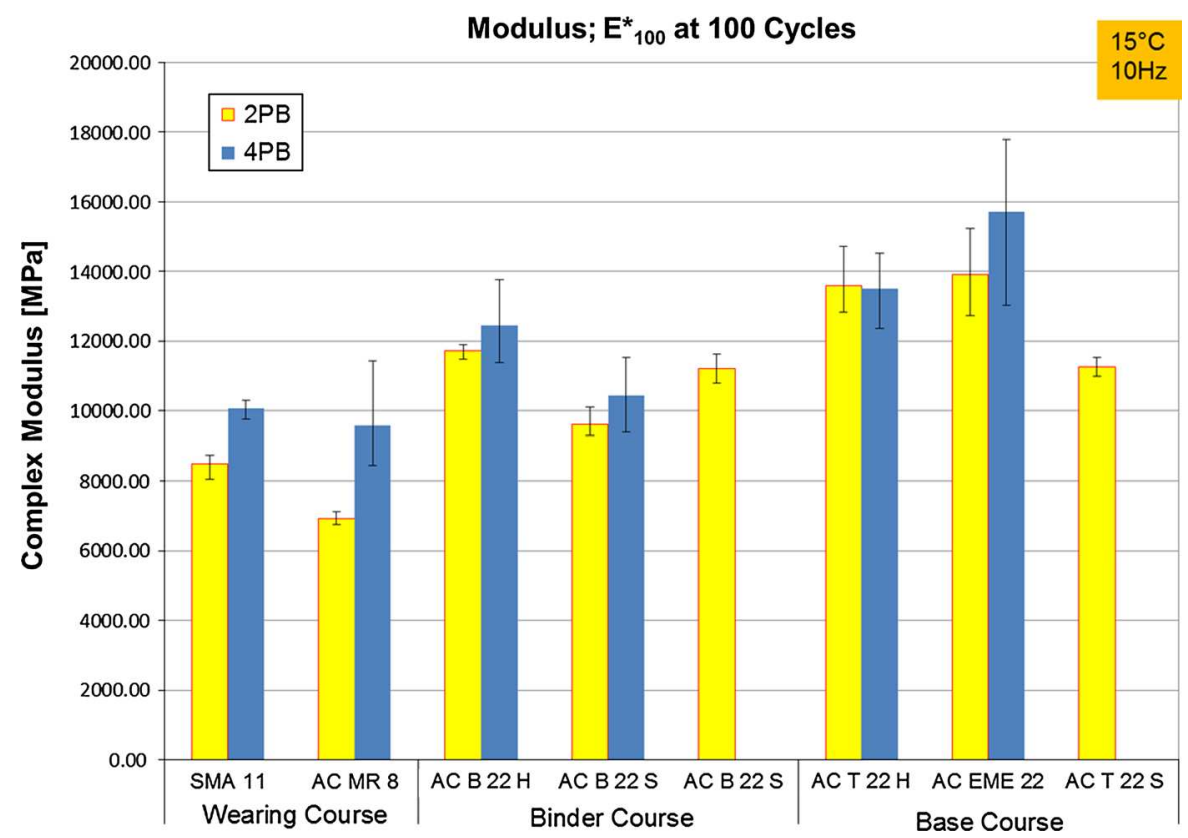


Fig. 6 Phase angle, $\Phi_{100}$, of all the materials tested at $15{ }^{\circ} \mathrm{C}$ and $10 \mathrm{~Hz}$ as required by the Swiss annex to the standard

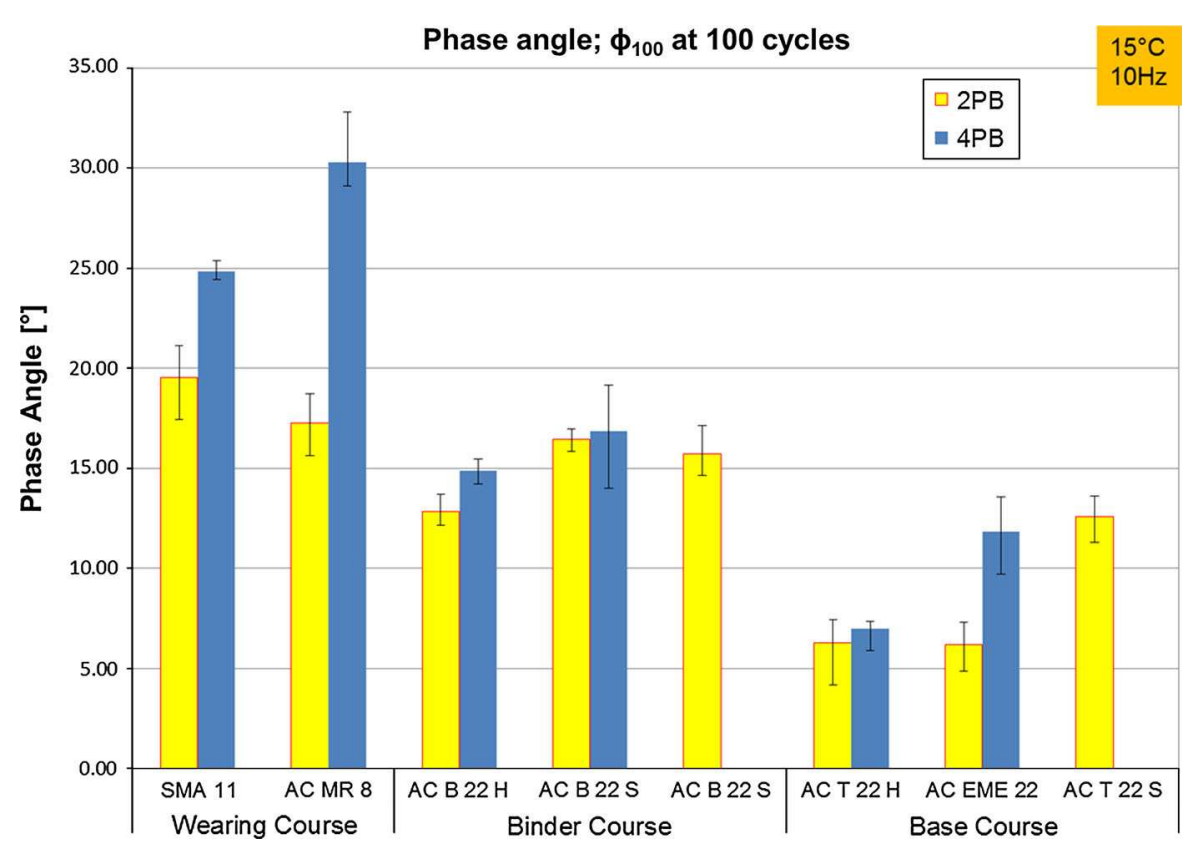

size attributes to the stiffness of the samples that also affect the results. A further factor affecting the results is the fact that the $2 \mathrm{~PB}$ specimens are glued whereas the 4PB specimens are clamped. Nevertheless, as shown in Figs. 7 and 8, for all data there is a good relationship between the $4 \mathrm{~PB}$ and the $2 \mathrm{~PB}$ results. The regression is shown in Eq. (1) for the complex stiffness modulus and (2) for phase angle:

$E_{100,4 \mathrm{~PB}}^{*}=1.081 E_{100,2 \mathrm{~PB}}^{*}\left(R^{2}=0.84\right)$,

$\Phi_{100,4 \mathrm{~PB}}=1.31 \Phi_{100,2 \mathrm{~PB}}\left(R^{2}=0.76\right)$,

where $E^{*}$ is the complex modulus, $\Phi$ is the phase angle and 100 indicates values at the 100th cycle as defined earlier as initial complex modulus and phase angle. Considering only all AC 22 specimen, a correlation coefficient $R^{2}$ of 0.91 and 0.92 exists for both complex modulus and phase angle that indicate better agreement between $4 \mathrm{~PB}$ and $2 \mathrm{~PB}$ results for this type of pavement material. Similarly, the regression curve for other materials, i.e. SMA, AC MR and AC EME is lower with 0.90 and 0.76 for complex modulus and phase angle respectively. These results do not corroborate the Rilem inter-laboratory study results comparing $4 \mathrm{~PB}$ and $2 \mathrm{~PB}$ at $20{ }^{\circ} \mathrm{C}$ and $10 \mathrm{~Hz}$ that indicate a decrease of $14 \%$ for modulus and increase of $18 \%$ for phase angle.

An overall impression can be obtained from Figs. 5 and 6. This figure shows all the materials tested at

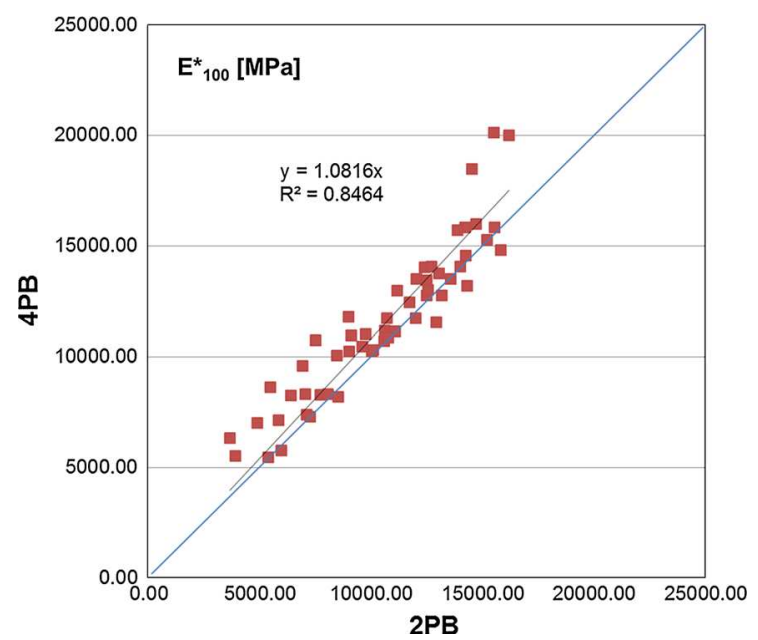

Fig. 7 Regression of initial complex modulus, $E_{100}^{*}$, between $4 \mathrm{~PB}$ and $2 \mathrm{~PB}$ tests for all data $\left(10,15,20^{\circ} \mathrm{C}\right.$ and $\left.3,10,25 \mathrm{~Hz}\right)$, equality line shown in blue. (Color figure online)

$15^{\circ} \mathrm{C}$ and $10 \mathrm{~Hz}$ as required by the Swiss annex to the standard. As seen, the scatter in the results (for 4PB) as well as difference between $2 \mathrm{~PB}$ and $4 \mathrm{~PB}$ was higher for AC MR 8 and AC EME 22. AC MR 8 samples used in $4 \mathrm{~PB}$ tests were the thinnest tested $(30 \times 30 \mathrm{~mm})$ with a rough surface (not cut). This sample size and the rough surface discussed below had an effect on the $4 \mathrm{~PB}$ results as the sample mass was, as a result, too small and the effect higher especially at $25 \mathrm{~Hz}$. The 


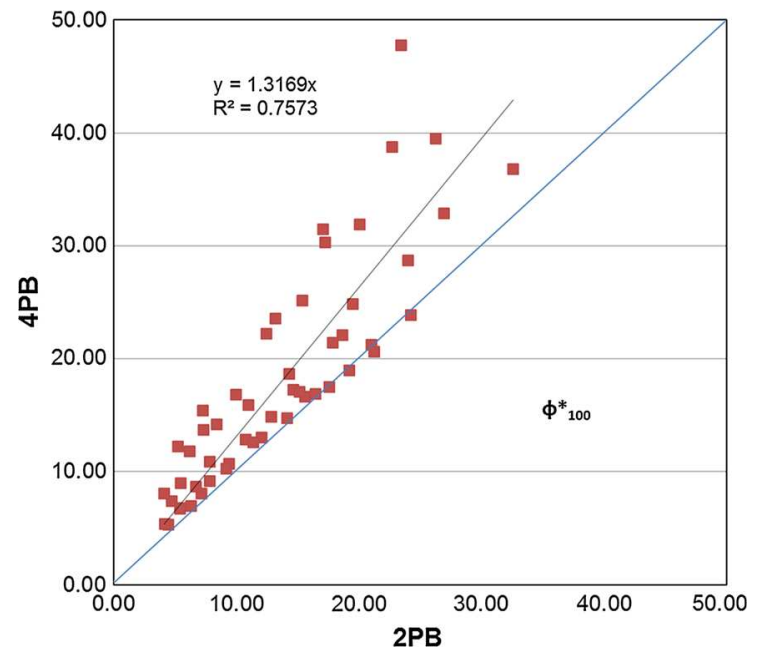

Fig. 8 Regression of initial phase angle, $\mathrm{E}^{*}{ }_{100}$ between $4 \mathrm{~PB}$ and $2 \mathrm{~PB}$ test for all data $\left(10,15,20^{\circ} \mathrm{C}\right.$ and $\left.3,10,25 \mathrm{~Hz}\right)$, equality line shown in blue

sample size of the $2 \mathrm{~PB}$ specimen was also limited $(25 \times 25)$ due to the layer thickness. Also, in this case, it was not possible to cut the top $20 \mathrm{~mm}$. In general, as shown, the scatter in the results is higher for 4PB than 2PB. In addition, if the results from 3 and $10 \mathrm{~Hz}$ are projected for $25 \mathrm{~Hz}$, the $4 \mathrm{~PB}$ complex modulus results at $25 \mathrm{~Hz}$ are below expected values and the phase angle at $25 \mathrm{~Hz}$ are above expected values. This can be attributed to the shape of the sine curve for the applied force as at this frequency the sine curve is not smooth and mathematical compensation can miss the peaks. The fact that the results at $25 \mathrm{~Hz}$ were independent of temperature shows that the origin of this problem is not due to the setup. The results look closer to the expected values in case of materials with higher complex moduli as discussed above (i.e. $>10,000 \mathrm{MPa}$ ).

Presentation of the results in terms of Black diagrams ( $\left|E^{*}\right|$ vs. $\phi$ ) allow elimination of the temperature factor and calculation of the linear visco-elastic modulus at zero phase angle. Table 3 summarizes the results of the Black diagrams and Fig. 9 shows an example for nine specimens for each test type for material B2. It can be seen that the linear visco- elastic modulus obtained from $2 \mathrm{~PB}$ and $4 \mathrm{~PB}$ tests are not equal in most cases. The difference is between zero and $36 \%$. However the slopes in the Black diagrams, i.e. the relationships between complex modulus $\left|E^{*}\right|$ and phase angle $\phi$, are similar. The slope of the ( $\left|\mathrm{E}^{*}\right|$ vs. $\left.\phi\right)$ are also an indication of the degree of viscosity. The results in Table 3 show that the base courses are more viscous than the binder and wearing courses.

Due to size limitations the two wearing courses $\mathrm{C} 1$ and D1 were not cut on the surface as required by the standards. This uncut surface has a negative effect on the results as it introduces more inhomogeneity and cracks as can be seen in more scatter in the results. This is especially noticeable at $25 \mathrm{~Hz}$ and in the phase angle values. On the other hand it reflects performance in a realistic way.

As shown in Figs. 5 and 6, the results from $2 \mathrm{~PB}$ tests for D2 and G3 were very similar to those obtained for other AC B 22 materials. Therefore further 4PB tests were not done on these materials.

\subsection{Fatigue}

During the fatigue tests, the complex modulus continuously reduces and the phase angle continually increases as shown in the example of Fig. 10 for AC B $22 \mathrm{H}$. The test is terminated when the complex modulus reaches $50 \%$ of its original value. This is an international standard as well as a European one. As discussed earlier, during a fatigue test, three distinct regions can be identified. In the example shown in Fig. 10, the first and second phase of this development can be clearly observed. As this particular test was terminated when the complex modulus reached the $50 \%$ value, no third phase can be seen. It can be observed from this data that the specimen's initial modulus defined at 100 cycles was 13'973 MPa, and final complex modulus was $6,960 \mathrm{MPa}$. There are some outliers that should be accounted for and disregarded in the data analysis so that the specimen is not considered already damaged too early. This is accounted for in the 4PB tests by defining failure when 20 consecutive measurements are below the failure criterion. In the $2 \mathrm{~PB}$ tests, this is accounted for by defining failure when 90 consecutive measurements are below the failure criterion. The different criteria are due to different experiences of the two labs.

A sample of the results of the experiments is shown in Fig. 11. The curves show the relationship between fatigue failure criteria $N_{\mathrm{f} / 50}$ (or specimen break) and applied strain amplitude $\varepsilon$. Fatigue data obtained using bending tests, where the stress or strain is repeated until the specimen fails, can be expressed using the Wöhler type fatigue line which was drawn by making 
Table 3 Pure linear visco-elastic modulus from black diagrams

\begin{tabular}{|c|c|c|c|c|c|c|c|c|c|}
\hline \multirow[t]{2}{*}{ Type } & \multirow[t]{2}{*}{ Layer } & \multirow{2}{*}{$\begin{array}{l}\text { Mix } \\
\text { Designation }\end{array}$} & \multicolumn{3}{|c|}{$E_{100}^{*} @ \Phi=0(\mathrm{MPa})$} & \multicolumn{2}{|c|}{ Regression $2 \mathrm{~PB}$} & \multicolumn{2}{|c|}{ Regression 4PB } \\
\hline & & & $2 \mathrm{~PB}$ & $4 \mathrm{~PB}$ & $\%$ diff & Slope & $R^{2}$ & Slope & $R^{2}$ \\
\hline \multirow[t]{2}{*}{ Wearing course } & SMA 11 & $\mathrm{C} 1$ & 17,123 & 16,284 & -5 & -420 & 0.97 & -231 & 0.63 \\
\hline & AC MR 8 & D1 & 14,622 & 18,957 & 30 & -429 & 0.97 & -315 & 0.98 \\
\hline \multirow[t]{3}{*}{ Binder course } & AC B $22 \mathrm{H}$ & B2 & 19,986 & 24,049 & 20 & -625 & 0.99 & -769 & 0.98 \\
\hline & AC B $22 \mathrm{~S}$ & $\mathrm{C} 2$ & 19,959 & 22,354 & 12 & -615 & 0.98 & -694 & 0.93 \\
\hline & AC $22 \mathrm{~S}$ & D2 & 21,852 & N/A & N/A & -652 & 0.99 & N/A & N/A \\
\hline \multirow[t]{3}{*}{ Base course } & AC T $22 \mathrm{H}$ & B3 & 19,679 & 19,767 & 0 & -985 & 0.99 & -886 & 0.93 \\
\hline & AC EME 22 & F3 & 19,695 & 26,728 & 36 & -917 & 0.99 & -895 & 0.98 \\
\hline & AC T $22 \mathrm{~S}$ & G3 & 21,345 & N/A & N/A & -789 & 0.97 & N/A & N/A \\
\hline
\end{tabular}

N/A not applicable

Fig. 9 Black diagram for AC B $22 \mathrm{H}$

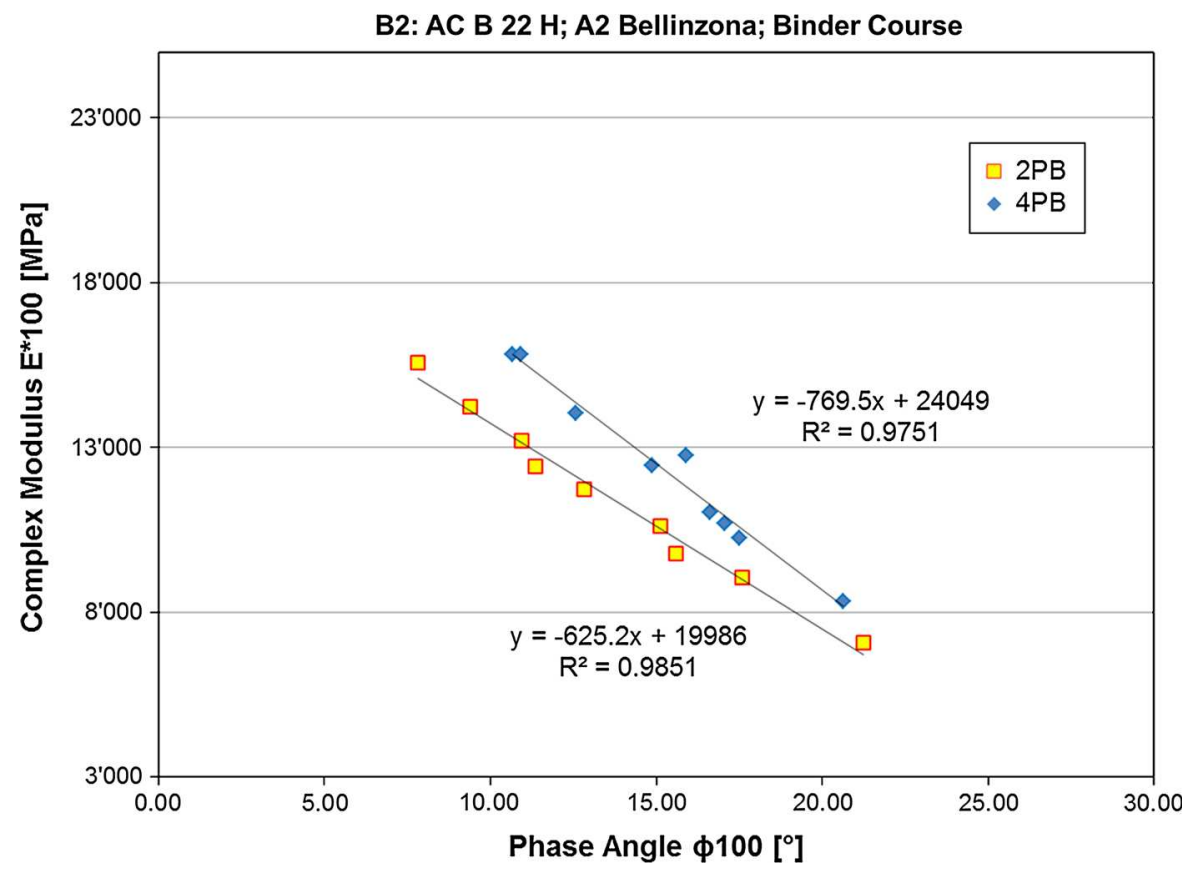

a linear regression between the decimal logarithms of $N_{i}$ and the decimal logarithms of $\varepsilon_{i}$ as defined in the standard and shown in Eq. (3):

$\log \left(N_{\mathrm{f}}\right)=a+\left(\frac{1}{b}\right) \cdot \log (\varepsilon)$,

where, $\varepsilon$ is the amplitude of the tensile strain repeatedly applied; $a$ and $b$ are material coefficients; and $N_{\mathrm{f}}$ is the number of load applications to failure. The material coefficient " $a$ " is the ordinate of the fatigue line and " $1 / b$ " is the slope. Table 4 shows the material constants of Eq. (3) as obtained from the 2PB and $4 \mathrm{~PB}$ tests for the tested samples. It is clear from these data that the material constants from the two types of experiments are not the same. From the material coefficients $a$ and $b$, the resistance to fatigue at 1 million cycles defined as $\varepsilon_{6}$ can be calculated from Eq. (3) and is shown in Table 4.

In general, the data in this study indicates that there is agreement only in some cases between the results obtained from the two tests as performed under this study. The difference in fatigue resistance obtained through $\varepsilon_{6}$ is shown in Table 4 . It can be seen that the $\varepsilon_{6}$ values vary between 6 and $63 \%$. This difference can be attributed in addition to the sample size and set up to the different test temperatures. 
Fig. 10 The development of complex modulus and phase angle during a $4 \mathrm{~PB}$ PR fatigue tests at $20{ }^{\circ} \mathrm{C}$ and $25 \mathrm{~Hz}$ (sample B21: AC B $22 \mathrm{H})$

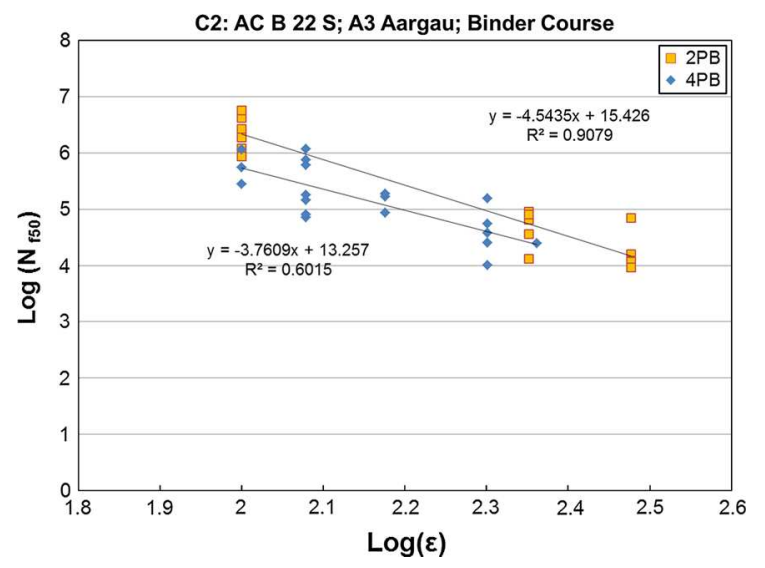

Fig. 11 Fatigue diagram showing relationship between fatigue failure criteria $N_{\mathrm{f} / 50}$ and applied strain amplitude $\varepsilon$ of four point bending $20^{\circ} \mathrm{C}$ and $25 \mathrm{~Hz}$ and two point bending at $10^{\circ} \mathrm{C}$ and $25 \mathrm{~Hz}$ for AC B $22 \mathrm{~S}$

As mentioned earlier the fatigue tests were planned to be at $20^{\circ} \mathrm{C}$ and $25 \mathrm{~Hz}$ for $4 \mathrm{~PB}$ tests and $10{ }^{\circ} \mathrm{C}$ and $25 \mathrm{~Hz}$ for $2 \mathrm{~PB}$. The temperature plays a significant role in the modulus values as shown in Sect. 4.1. Thus it can be expected that the fatigue behavior of the two tests would be different. Nevertheless for section D1 the temperature was reduced to $10{ }^{\circ} \mathrm{C}$ as the cross section of the samples $(30 \mathrm{~mm} \times 30 \mathrm{~mm})$ made them too weak for the 4 PB test setup. As shown in Fig. 12 at $10{ }^{\circ} \mathrm{C}$ there is good agreement between the $4 \mathrm{~PB}$ and $2 \mathrm{~PB}$ results. The largest difference in the fatigue

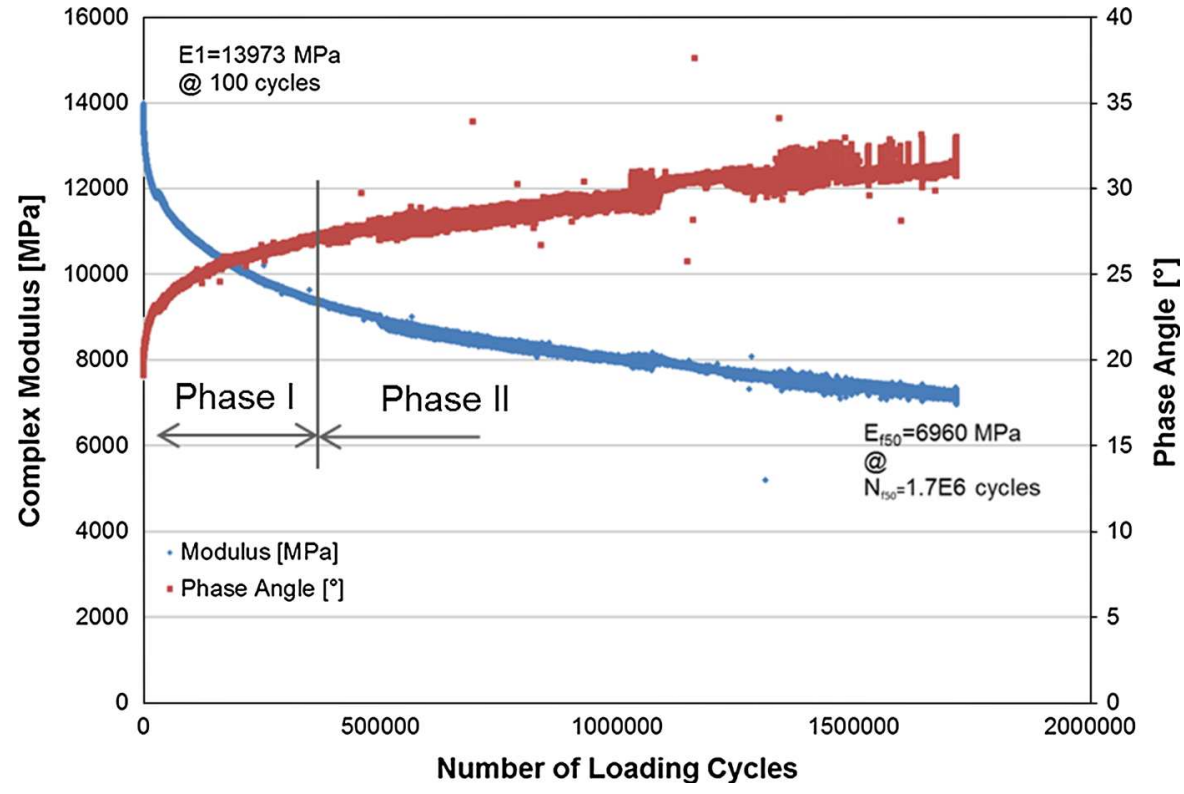

curves was seen for SMA11. This difference is also partially due to temperature as well as the small size of the wearing course specimens $(40 \mathrm{~mm} \times 40 \mathrm{~mm})$ which made them also weak for the 4PB setup, thus producing a large scatter. Furthermore, this is in addition due to the uncut top surface as discussed in the previous section. On the other hand the tested samples reflect actual field conditions regarding sample size and shape and therefore provide an opportunity to test specimen with field properties.

Figure 12 presents the values of strain $\varepsilon_{6}$ at one million cycles, an indication of fatigue resistance for all materials tested. In most cases, the ranking obtained is dissimilar. It is important to note that the age and the field performance history of the samples play a role in defining fatigue life and resistance to fatigue. For example AC MR 8 (D1) was 1 year in service and has the highest value of $\varepsilon_{6}$ whereas $\mathrm{AC} \mathrm{B}$ $22 \mathrm{~S}$ (C2) was already 11 years in service with a lower $\varepsilon_{6}$. The ranking obtained by $4 \mathrm{~PB}$ indicates AC MR 8 as the most fatigue resistant and SMA11 as the least. This ranking is dissimilar with the $2 \mathrm{~PB}$ one where also $\mathrm{AC}$ MR 8 is ranked highest with $\mathrm{AC} \mathrm{T} 22$ being the least fatigue resistant.

\section{Conclusions}

Results of a Swiss inter-laboratory study of $2 \mathrm{~PB}$ and $4 \mathrm{~PB}$ tests for complex modulus and fatigue conducted 
Table 4 Material constants and $\varepsilon_{6}$ obtained from $4 \mathrm{~PB}$ and $2 \mathrm{~PB}$ based on Eq. (3) $2 \mathrm{~PB}-\mathrm{TR}$ at $10{ }^{\circ} \mathrm{C}, 4 \mathrm{~PB}-\mathrm{PR}$ at $20{ }^{\circ} \mathrm{C}$ both at $25 \mathrm{~Hz}$

\begin{tabular}{|c|c|c|c|c|c|c|c|c|c|c|c|}
\hline \multirow[t]{2}{*}{ Type } & \multirow[t]{2}{*}{ Layer } & \multirow{2}{*}{$\begin{array}{l}\text { Mix } \\
\text { Desig. }\end{array}$} & \multicolumn{3}{|l|}{$2 \mathrm{~PB}$} & \multicolumn{3}{|l|}{$4 \mathrm{~PB}$} & \multicolumn{2}{|l|}{$\varepsilon_{6}$} & \multirow{2}{*}{$\begin{array}{l}\% \text { Diff } \\
\text { In } \varepsilon_{6}\end{array}$} \\
\hline & & & $a$ & $1 / b$ & $R^{2}$ & $a$ & $1 / b$ & $R^{2}$ & $2 \mathrm{~PB}$ & $\overline{4 \mathrm{~PB}}$ & \\
\hline \multirow[t]{2}{*}{ Wearing course } & SMA 11 & $\mathrm{C} 1$ & 20.2 & -6.6 & 0.95 & 9.6 & -2.1 & 0.24 & 142 & 52 & 63 \\
\hline & AC MR 8 & D1 & 22.4 & -7.2 & 0.86 & $20.4^{\mathrm{a}}$ & $-6.4^{\mathrm{a}}$ & $0.79^{\mathrm{a}}$ & 190 & $178^{\mathrm{a}}$ & 6 \\
\hline \multirow[t]{3}{*}{ Binder course } & AC B $22 \mathrm{H}$ & B2 & 20.7 & -6.96 & 0.95 & 21.74 & -7.2 & 0.85 & 129 & 154 & -19 \\
\hline & AC B $22 \mathrm{~S}$ & $\mathrm{C} 2$ & 15.43 & -4.50 & 0.91 & 13.26 & -3.76 & 0.6 & 125 & 85 & 32 \\
\hline & AC B $22 \mathrm{~S}$ & D2 & 20.2 & -6.40 & 0.83 & & & & 165 & & \\
\hline \multirow[t]{3}{*}{ Base course } & AC T $22 \mathrm{H}$ & B3 & 18.16 & -6.04 & 0.8 & 19.02 & -6.8 & 0.22 & 103 & 82 & 20 \\
\hline & AC EME 22 & F3 & 25.44 & -9.23 & 0.86 & 17.98 & -5.62 & 0.89 & 128 & 135 & -6 \\
\hline & $\mathrm{AC} T 22 \mathrm{~S}$ & G3 & 15.73 & -4.81 & 0.84 & & & & 105 & & \\
\hline
\end{tabular}

${ }^{\text {a }}$ Values at $10^{\circ} \mathrm{C}$ and $10 \mathrm{~Hz}$

Fig. 12 Fatigue resistance $\varepsilon_{6}$ at one million cycles for 2PB (at $10{ }^{\circ} \mathrm{C}$ ) and 4PB (at $20^{\circ} \mathrm{C}$ ) tests, with the exception of $4 \mathrm{~PB}$ AC MR 8 at $10{ }^{\circ} \mathrm{C}$

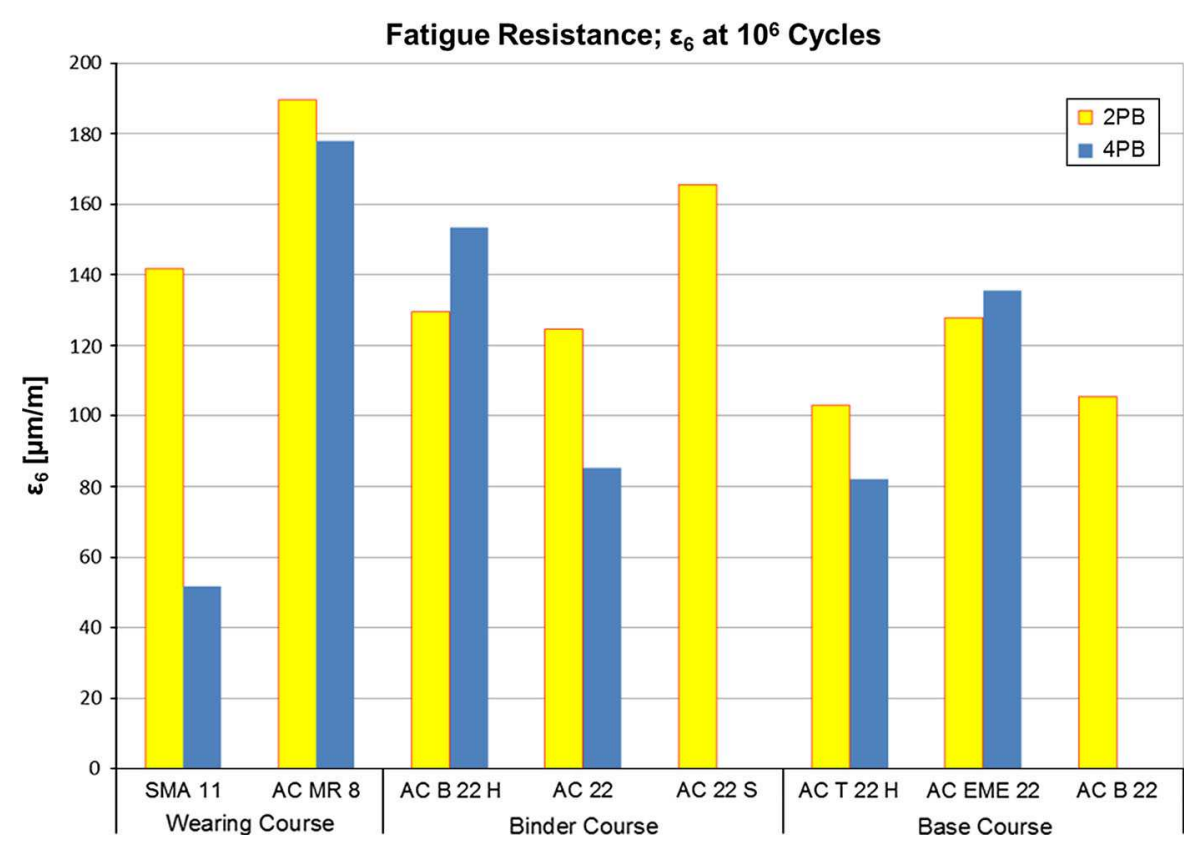

on a wide pallet of specimen produced from pavement slabs cut from aged field sections were presented. These tests on slabs where performance was known allowed to link lab fatigue behavior with real in situ behavior. It was shown that the European standard requirements pertaining to sample size, NMAS and cut surfaces are not always practically applicable when field slabs are considered.

The results show more scatter in the data of $4 \mathrm{~PB}$ tests in comparison to $2 \mathrm{~PB}$ tests. Using the regression comparing complex modulus values of $4 \mathrm{~PB}$ and $2 \mathrm{~PB}$ it was shown that $4 \mathrm{~PB}$ values were about $8 \%$ higher than $2 \mathrm{~PB}$ tests. A linear regression between $2 \mathrm{~PB}$ and 4PB tests with correlation coefficient $R^{2}$ of 0.84 for complex modulus and 0.76 for phase angle was determined. The complex modulus results of $4 \mathrm{~PB}$ tests at 3 and $10 \mathrm{~Hz}$ loading frequency were in agreement with $2 \mathrm{~PB}$ however at $25 \mathrm{~Hz}$ the $4 \mathrm{~PB}$ results were below expected values in some cases. Black diagrams showed that the linear visco- elastic modulus obtained from $2 \mathrm{~PB}$ and $4 \mathrm{~PB}$ tests were not equal in most cases. The difference was between zero and 
$36 \%$. However the slopes in the Black diagrams, i.e. the relationships between complex modulus $\left|E^{*}\right|$ and phase angle $\phi$, were similar.

The difference in fatigue resistance obtained through $\varepsilon_{6}$ showed that the $\varepsilon_{6}$ values obtained by $2 \mathrm{~PB}$ and $4 \mathrm{~PB}$ vary between 6 and $63 \%$. In addition the ranking with regard to fatigue resistance was dissimilar. The material coefficient " $a$ ", the ordinate of the fatigue line and " $1 / b$ " the slope obtained from the $2 \mathrm{~PB}$ and $4 \mathrm{~PB}$ tests showed that the material constants from the two types of experiments are not the same.

The values obtained for AC EME 22 fulfill the only requirement for complex modulus $\left(E_{100}^{*}\right)$ and resistance to fatigue $\left(\varepsilon_{6}\right)$ in the Swiss standards. It is important to note that these tests were performed on aged specimen from the road and actual complex modulus and resistance to fatigue values for production of new materials can be different from these.

The two wearing courses with 40 and $30 \mathrm{~mm}$ depth were tested and results presented. However, wearing courses of Swiss motorways are not subjected to fatigue failure in bending mode and from a practical point of view there is no need to evaluate their fatigue performance. In general, determining fatigue bending properties of pure wearing courses for pavements with stiff base and sub-bases is not recommended. On the basis of the obtained results the validity of performance based standards using one test method is discussed and it is recommended that test specific performance standards be developed as the different tests result in different requirements. As a result of this research project a follow up project is defined where performance oriented requirements for various types of Swiss pavements will be developed. Furthermore, comparisons between laboratory measured fatigue life and the field fatigue service life should be made.

Acknowledgments This research project was supported by the Swiss Roads Office (FEDRO) grant number VSS 2006/503. The authors would like to acknowledge the help of Simon Kuentzel, Andreas Treuholz and Martin Hugener in performing the experiments in this project at Empa. The specimen were cut and prepared by Christian Meierhofer and Roland Takacs. At LAVOC, data analysis and specimen preparation were done by Jean-Claude Reymond and Jean-Wilfried Fils-Aimé.

\section{References}

1. Partl MN et al (eds) (2013). Advances in inter-laboratory testing and evaluation of bituminous materials. State of the Art Report of the Rilem Technical Committee 206-ATB

2. EN 12697-26 (2012) Bituminous mixtures-test methods for hot mix asphalt-part 26: stiffness

3. EN 12697-24 (2007) 2004+A1, bituminous mixtures-test methods for hot mix asphalt-part 24: resistance to fatigue

4. Wu H, Huang B, Shu X (2014) Document characterizing fatigue behavior of asphalt mixtures utilizing loaded wheel testers. J Mater Civ Eng 26(1):152-159

5. Di Benedetto H, de La Roche C, Baaj H, Pronk A, Lundström R (2004) Fatigue of bituminous mixtures. Mater Struct 37:202-216

6. Pittet M (2000) Essais d'exactitude pour essai de module complexe et essai de fatigue pour normes EN 12697-24 et EN 12697-26. Détermination de la répétabilité et de la reproductibilité

7. Pittet M (2006) A2 Erstfeld-Amsteg. Module et résistance à la fatigue d'un enrobé AC EME $22 \mathrm{C} 1$

8. Gubler R, Partl MN, Canestrari F, Grilli A (2005) Influence of water and temperature on mechanical properties of selected asphalt pavements. Mater Struct 38:523-532

9. Pais J (ed) (2009) Four point bending proceedings of the second workshop. University of Minho, Guimaraes. 24-25th Sept 2009

10. AkhtarhuseinTayebali A, Deacon JA, Monismith CL (1996) Development and evaluation of dynamic flexural beam fatigue test system. Transp Res Rec 1545:89-97

11. Puchard Z, Gorgenyi A (2012) Hungarian experience with different bending devices. In: Pais JC (ed) Four-point bending. Taylor and Francis Group, London

12. SN 640 431-1b-NA, Bituminous mixtures- material specifications- part 1: aspahlt concrete National Annex. Asphaltmischgut- Mischgutanforderungen-teil 1: Asphaltbeton; nationaler Anhang available in German and French

13. Pais C, Harvey JT (2012) Four point bending. CRC Press, Taylor and Francis, Davis

14. Matthews JM, Monismith CL, Craus J (1993) Investigation of laboratory fatigue testing procedures for asphalt aggregate mixtures. J Transp Eng 119(4):634-654

15. Picado-Santos L, Almeida A, Pais J, Antunes ML, Batista F (2009) Assessment of stiffness and fatigue tests in Portugal. In: Pais J (ed) Four point bending proceedings of the second workshop. University of Minho, Guimaraes. 24-25th Sept 2009

16. Francken L (ed) 1998 Bituminous binders and mixes. Rilem Report 17. E \& FN Spon, London

17. Dondi G, Pettinari M, Sangiorgi C, Zoorob S (2013) Traditional and dissipated energy approaches to compare the $2 \mathrm{~PB}$ and $4 \mathrm{~PB}$ flexural methodologies on warm mix asphalt. Constr Build Mater 47(2013):833-839 